\title{
TIPOLOGÍA Y ORGANIZACIÓN DEL PAISAJE EN MUNTANYES D'ORDAL (BARCELONA)
}

\author{
David Serrano Giné \\ Departament de Geografia. Universitat Rovira i Virgili. Tarragona \\ david.serrano@urv.cat
}

\section{RESUMEN}

Se presentan las características principales del paisaje de Muntanyes d'Ordal (Barcelona), fijando especial atención en su organización espacial. Para ello se adopta una metodología de tipo sistémico, que parte de considerar elementos y energías estructurantes en base a criterios de homogeneidad dinámica y funcionalidad, y que se organiza en tres rangos taxonómicos. Durante la argumentación del artículo se presta un particular cuidado a cuestiones de índole metodológica.

Palabras clave: paisaje, unidad de paisaje, elementos y energías, taxonomía, Muntanyes d'Ordal.

\section{ABSTRACT}

The main characteristics of Muntanyes d'Ordal (Barcelona) landscape are shown, paying special attention to their spatial organization. For it a system approach has been adopted, leaving particular consideration to structural elements and energies, adopting criteria of dynamics, homogeneity and functionality, and organizing the landscape approach in three taxonomic ranks. During the argumentation special attention is paid to methodology.

Key words: landscape, landscape unit, elements and energies, taxonomy, Muntanyes d'Ordal.

Fecha de recepción: junio 2011.

Fecha de aceptación: diciembre 2012. 


\section{INTRODUCCIÓN}

El Convenio Europeo del Paisaje, firmado en Florencia el año 2000 y ratificado por España en 2008, define el paisaje como cualquier parte del territorio, tal como es percibida por las poblaciones, cuyo carácter resulta de la acción de factores naturales y/o humanos y de sus interrelaciones (MAE, 2000:3). Más allá de este prudente enunciado, el paisaje acostumbra a entenderse como la realidad, y también como la percepción, que emana de integrar lo biofísico y lo sociocultural y que, ante todo, posee un protagonismo caudal en la formación y el mantenimiento de la identidad de un territorio.

Bajo esta coyuntura, disciplinas de carácter territorial, como la Geografía, han fijado una atención especial al estudio del paisaje. Tanto es así que Julio Muñoz (1981: 58) afirma que «es lógico que sea el paisaje, entendido como manifestación observable del estado de dicho sistema, su punto de partida fundamental, el eje de su investigación». En los últimos años esta atención parece haberse reforzado, la dimensión del paisaje ha sobrepasado la esfera de lo ambiental y lo territorial y, cada vez más, impregna ámbitos de marcado carácter cultural y político. Àlex Tarroja (2006:41) habla de un «redescubrimiento del paisaje», donde dicho concepto resulta propicio para religar y encubrir inquietudes sociales y territoriales, siempre en la doble acepción, la objetiva y la subjetiva, desde la que acostumbra a entenderse. Un renovado interés que aumenta cuando se analizan las implicaciones en ordenación del territorio (Zoido, 1998), en gestión de espacios sensibles, como zonas de montaña (Mas Hernández, 2000) o áreas metropolitanas (Llop, 2008), en la conformación de valores patrimoniales (Elías, 2008), en su importancia en salud y bienestar (Pol, 2008 et al.) o en el peso que ostenta desde su más amplia dimensión territorial (Nogué, 2010).

\subsection{Conceptualización del paisaje en Geografía}

La consideración del paisaje en Geografía debe entenderse prestando atención a su etimología que, como ya se ha notado, se vincula fuertemente al campo semántico de la tierra y, por extensión, lo territorial (Paül, Sancho y Tort, 2011). La tradición fija a Humboldt como la figura de referencia que engarza el estudio del paisaje con las tendencias academicistas del siglo XIX, siempre desde el planteamiento romántico propio de la época. Autores como Haeckel, Ritter o Troll, entre otros, ayudaron a perfilar el tratamiento del paisaje de manera sistemática (Bolòs y Gómez Ortiz, 2009; Serrano y Bennassar, 2009), por bien que no es hasta su adopción por académicos rusos que el paisaje pasa a considerarse de forma rigurosa como objeto de estudio de la Geografía (Frolova, 2001).

Aportaciones como la de Gustav Fochler-Hauke (1953) dejan patente la construcción epistemológica del paisaje sobre los conceptos de unidad temática y territorial. Así, tomando como referencia autores como Passarge, Sauer y Sclüter, Fochler-Hauke subraya explícitamente la idea de globalidad con la que inicialmente se concebía el paisaje: «las ideas filosóficas de la totalidad de los fenómenos han ganado particularmente influencia sobre la Geografía, fomentando el nacimiento del concepto que una Corología con leyes propias sólo es realizable, si el «ser» del paisaje es percibido como una estructura íntegra de relaciones y definida en forma particular» (Fochler-Hauke, 1953:8). Desde estas premisas se conoce un buen número de líneas de investigación y escuelas de trabajo que toman el paisaje como 
objeto de estudio. Arturo García y Julio Muñoz (2002) agrupan la dispersión de propuestas en tres planteamientos de estudio: vía sumativa, vía ecológica y vía sistémica. La primera de ellas, la vía sumativa, se acerca al paisaje desde el historicismo, entendiéndolo como una excepcionalidad única e irrepetible y desde una posición netamente corográfica. La segunda, la vía ecológica, mantiene dicho carácter historicista, si bien se centra en las relaciones ser humano-medio y en las configuraciones que se le derivan. Finalmente, la vía sistémica entiende el paisaje como una realidad funcional y dinámica, integrada por elementos biofísicos y socioeconómicos interrelacionados. En el seno de esta concepción conviene distinguir tres enfoques diferenciados: la Ciencia del geosistema, el Reconocimiento de territorios y los Estudios integrados.

La Ciencia del geosistema se configura bajo la influencia de la Teoría general de sistemas y concibe la superficie terrestre de una manera unitaria y adimensional, definida por flujos de materia y energía que conforman «geohorizontes» y «geofaces», y que pueden estudiarse a través de métodos cuantitativos (Mateo, 1984). El Reconocimiento de territorios, por su parte, se basa en aproximaciones fisiográficas desde una perspectiva holística, donde lo abiótico toma una importancia particular; según la clasificación de Colin Mitchell (1991), se trata de un método basado en el uso de parámetros de referencia. Finalmente, los Estudios integrados utilizan el paisaje como herramienta de conocimiento territorial; consideran el territorio como un sistema, cuya morfología es el resultado de su funcionamiento y donde es posible diferenciar tres subsistemas (abiótico, biótico y antrópico) en mutua dependencia.

Los Estudios integrados se vinculan fuertemente a Georges Bertrand que, partiendo de la tradición historicista francesa, los estructuró sobre el concepto de geosistema. Se acostumbra a considerar a Eduardo Martínez de Pisón, Maria de Bolòs, Julio Muñoz y Valentín Cabero como los introductores de los estudios de paisaje en España siendo, precisamente, la vía sistémica el enfoque metodológico preferentemente adoptado (Gómez Mendoza, 2003:5). Ejemplo de ello son los trabajos pioneros de Juan Ignacio Plaza Gutiérrez (1984) en el Alto Aliste (Zamora), de José Manuel Llorente (1985) en la dehesa salmantina o de María Eugenia Arozena (1990) en la isla de La Gomera, entre muchos otros. Más recientemente se cuentan las experiencias de Jesús Saz (2001) en el entorno de los ríos Pancrudo y Jiloca (Teruel), de Emma Pérez-Chacón y colaboradores en el noreste de Gran Canaria (2005) y de Maria de Bolòs y Antonio Gómez en el Pirineo catalán (2006), por citar únicamente tres ejemplos.

Desde sus inicios, y entroncando con una realidad detectada y heredada de discípulos de Dokuchaiev, el planteamiento clásico del método sistémico ha sido tachado de ser excesivamente dual, por no saber congeniar las esferas de lo social y lo natural de manear efectiva. A pesar de que trabajos tempranos, como el de Pérez-Chacón y Suárez Rodríguez (1993), concilian estas desviaciones inteligentemente, la conceptualización de lo social y lo natural, lo objetivo y lo atribuido, según el planteamiento de Roger (2000), se compila en el llamado sistema GTP (geosistema-territorio-paisaje), que «sitúa el paisaje en un contexto geográfico» (Bertrand, 2000: 62). El sistema GTP, en efecto, relaciona el llamado «geosistema-fuente», o trabazón del paisaje en sentido estricto, con el territorio o, en palabras de Bertrand, con la lectura del mismo en tanto que recurso territorial; y ambos aspectos con la imagen que transmiten y que de ellos se percibe. Se trata, pues, de un planteamiento conceptual y epistemológico renovado, que reúne y religa de modo claro tres aproximaciones básicas al paisaje (Bertrand y Bertrand 2006). 
Bajo este mismo prisma, precisamente, se observan otros planteamientos de trabajo que, sin atender de manera explícita a los postulados de los Estudios integrados, sí recogen una parte sustancial de sus premisas y las reelaboran en una síntesis de carácter totalizador. Estos ejercicios, que en muchas ocasiones presentan un carácter sectorial o que focalizan en una temática concreta, no olvidan esta integración inherente al paisaje, y la vehiculan a través de, por ejemplo, las estrategias de intervención (Cruz y Español, 2009), la ordenación territorial (Nogué, Puigbert y Bretcha, 2009) o las políticas de protección y gestión (Frolova, Menor y Cáncer, 2003), fijando un énfasis especial en la complejidad de acepciones que convergen en el seno del paisaje y aprovechando la multiplicidad de planteamientos que permite desarrollar.

\section{OBJETIVOS}

El propósito general de este estudio es identificar, caracterizar y catalogar de manera detallada el paisaje de Muntanyes d'Ordal, desde una perspectiva global e integrada y partiendo del marco conceptual de la Teoría general de sistemas.

A tal efecto se han seleccionado los elementos que estructuran con mayor peso el área de estudio, a saber: el relieve, como soporte de la actividad biótica y antrópica; la vegetación, en calidad de indicador ambiental; y las actividades humanas pasadas y actuales, atendiendo a su indiscutible papel de modeladoras del paisaje. La información sobre estos aspectos se ha obtenido a partir de consultas bibliográficas y mediante un trabajo de campo exhaustivo. En el desarrollo de la investigación se ha considerado de manera especial la cartografía, motivo por el cual el uso de sistemas de información geográfica ha resultado de gran utilidad.

\section{III. ÁREA DE ESTUDIO}

El ámbito de trabajo se localiza en la parte central del sistema montañoso costero catalán, a pocos kilómetros de la ciudad de Barcelona y en plena Región Metropolitana (Fig. 1). En concreto nos referimos a poco más de 15.000 Ha repartidas en trece municipios pertenecientes a las comarcas de Baix Llobregat, Alt Penedès y Vallès Occidental, todas ellas en la provincia de Barcelona. El carácter periurbano del sector se manifiesta en la elevada densidad media poblacional, que en 2007 se cifraba en 967,6 habitantes $/ \mathrm{km}^{2}$, y se evidencia en la dispersión de espacios edificados (que ocupan un 17,15\% de la superficie total) y la profusión de redes viarias (Fig. 2).

El relieve del lugar se estructura en una sucesión de sierras de poca envergadura (sólo en puntos concretos se superan los 600 metros de altitud) articuladas alrededor de un punto central (Puig d'Agulles, 653,1 m) e independizadas entre sí por una profusión de torrentes y rieras, de régimen irregular, que desaguan en el Llobregat y el Anoia, su tributario. El conjunto aparece bien diferenciado de los llanos circundantes, como la depresión del Penedés y el delta del Llobregat, y es limítrofe con el conocido macizo de Garraf.

Los materiales dominantes yacen sobre un basamento de pizarras y esquistos del Cambro-Ordoviciano, con profusión de diques de cuarzo y un claro buzamiento en dirección noreste. Sobre la serie paleozoica se dispone una orla de materiales triásicos; por orden de antigüedad se distinguen cinco pisos de facies germánica, claramente estratificados y bien 
Figura 1

ÁREADE ESTUDIO

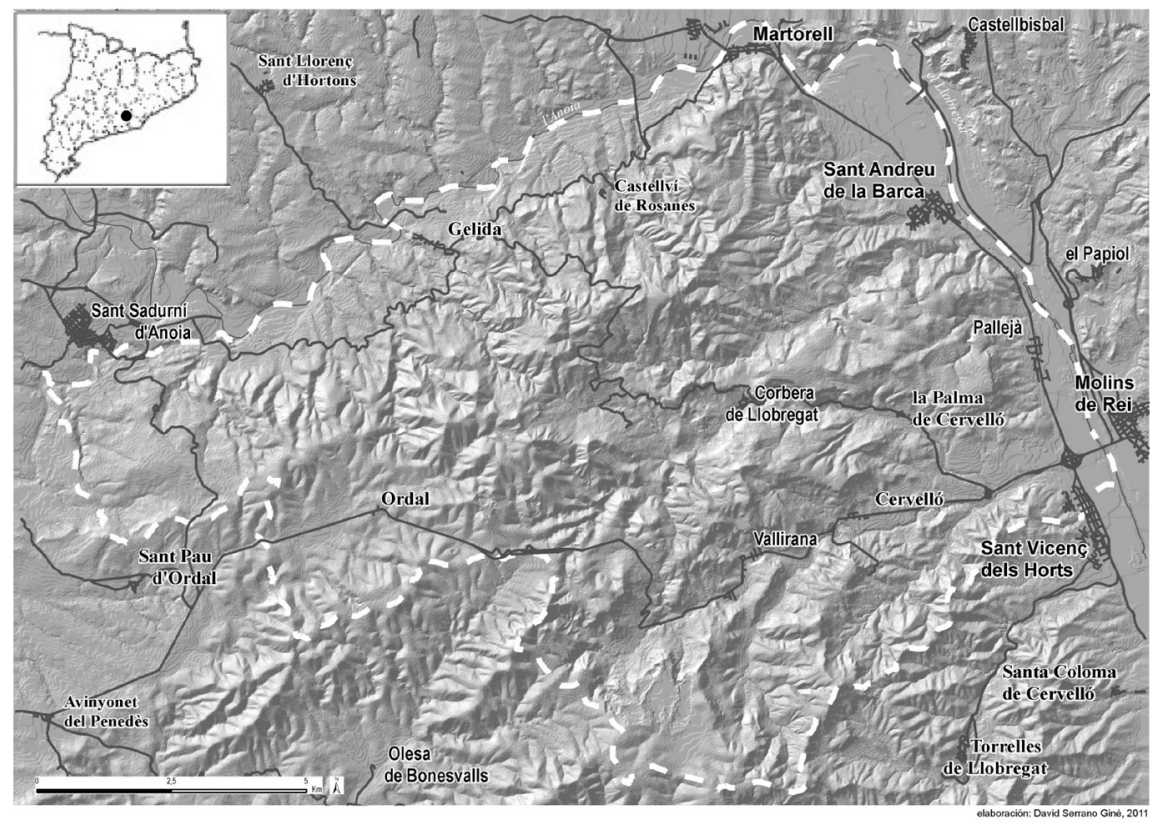

Figura 2

MEANDRO DE CA N'ALBAREDA, RIOO LLOBREGAT

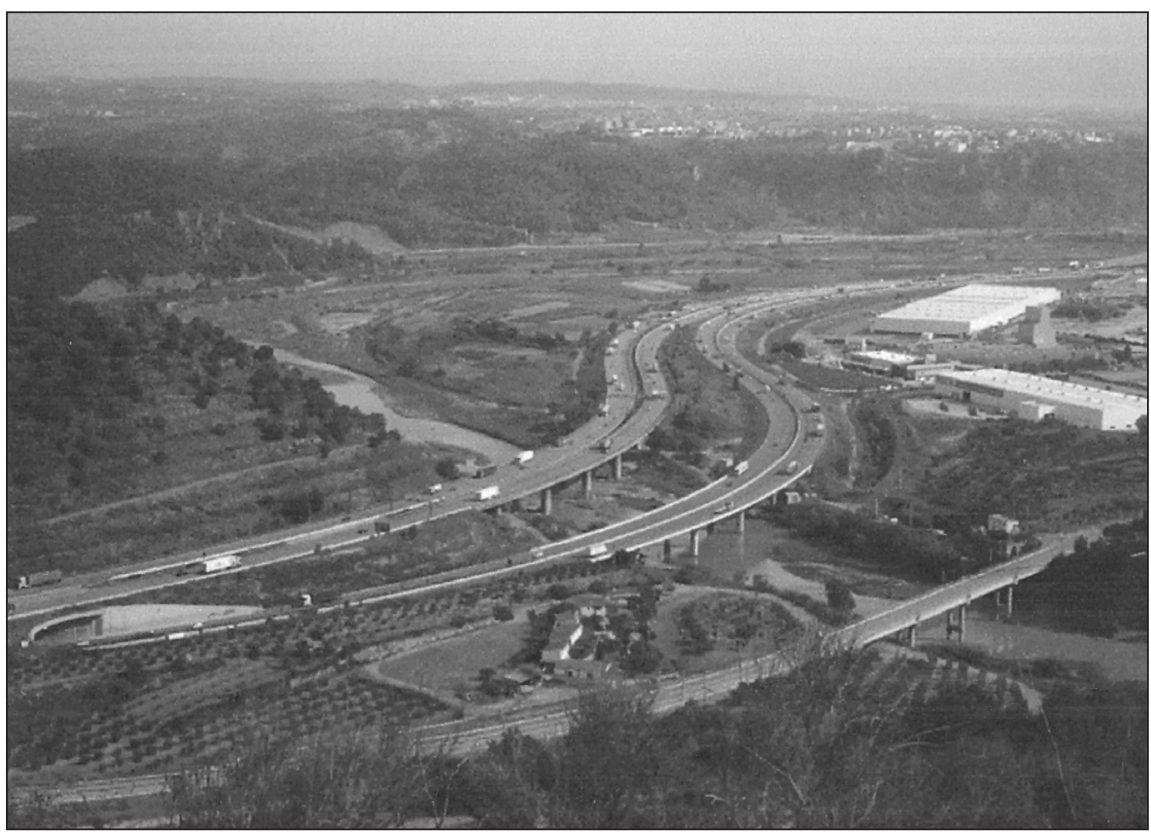


ejemplificados por lutitas y conglomerados del Buntsandstein, y por materiales calizos del Muschelkalk y arcillas y evaporitas del Keuper. Finalmente, a modo de cobertura, aparecen calizas y dolomías cretácicas, con una distribución y un grosor creciente hacia el suroeste (Llopis Lladó, 1947; Solé Sabarís, 1975; Marquès, 1995).

De esta manera el volumen y la disposición de los cuerpos montañosos marcan la transición entre una situación climática mediterránea litoral, hacia el sur, y otra ligeramente continentalizada, hacia el norte, añadiéndose a este cambio de situaciones el incremento de precipitación y el descenso térmico habitual en las zonas montañosas. Tal es así, que se ha llegado a hablar de una pequeña excepción en Muntanyes d'Ordal (Clavero et al., 1994) de la «dorsal pluviométrica meridiana catalana» o isoyeta de los $700 \mathrm{~mm}$ (Martín Vide y Moreno, 1996). En efecto, el observatorio de Begues registra una temperatura mediana de $12,7^{\circ}$ con una mínima de $5,5^{\circ}$ en enero y una máxima de $21,3^{\circ}$ en julio y agosto, cifrando las lluvias en $695,5 \mathrm{~mm}$.

La cubierta vegetal se corresponde con estas condiciones climáticas de transición, quedando constituida, mayormente, por formaciones boscosas secundarias de Pinus halepensis y por comunidades de Quercus ilex en distinto grado de madurez. En los ambientes de tendencia seca y cálida se constata la presencia de comunidades arbustivas de Quercus coccifera y de elementos termófilos, como Chamaerops humilis o Ampelodesma mauritanica; por otra parte, en los ambientes de tendencia relativamente húmeda y fresca se notan pequeñas agrupaciones de Quercus cerrioides, así como pies dispersos de Ilex aquifolium y Sorbus torminalis.

El aprovechamiento agrícola del lugar se remonta a la Alta Edad Media, y queda reflejado en un poblamiento disperso bien estructurado, concretizado por numerosas masías. Según el catastro de Patiño, a principios de mil ochocientos el cultivo más extendido eran los cereales por bien que, durante el siglo XIX y hasta la llegada de la filoxera (1886), las explotaciones tendieron al monocultivo vitícola (Serrano, 2006). Como otros muchos lugares cercanos a grandes ciudades, durante la segunda mitad del siglo XX Muntanyes d'Ordal fue objeto de un intenso proceso urbanizador que, en la actualidad, se manifiesta en urbanizaciones residenciales de carácter extensivo. En conjunto se cuentan más de sesenta urbanizaciones que, globalmente, significan el 77,64\% de la superficie edificada del sector. Su rasgo común es la dispersión de localizaciones, la dificultad de acceso y la existencia de un número muy significativo de viviendas de autoconstrucción que, hasta tiempos recientes, carecían de servicios básicos (Paül y Serrano, 2005). La defensa de los valores naturales y culturales ha sido objeto de un animado movimiento asociativo (Serrano y Piquer, 2006), fruto del cual han resultado distintos estudios de ámbito local y de sensibilización ciudadana. Desde el punto de vista de la legislación ambiental, el Pla d'Espais d'Interès Natural, de 1992, de la Generalitat de Catalunya ampara tres sectores disyuntos que, a partir de 2007, se encuentran reforzados por el LIC Serres del Litoral Central, de la Red Natura 2000.

\section{METOdOLOGÍA}

Como ya se ha avanzado el método seguido es sistémico, se inspira en la propuesta de Estudios integrados (Bertrand, 1968; Bolòs, 1992) y se matiza con el procedimiento seguido por Christian y Stewart (1968) en Reconocimiento de territorios. 
Se ha partido del estudio detallado de los elementos estructurantes del paisaje que, como se ha anunciado, son el relieve, la vegetación y la ocupación pasada y actual del suelo. Estos elementos han sido matizados por otros, también importantes pero secundarios, como es el caso del clima, el tipo de suelo o los valores sociales. La delimitación de unidades de paisaje se ha realizado a partir de la categorización de dichos elementos, mediante una ficha de campo sistematizada y adoptando criterios de homogeneidad dinámica y funcionalidad. La caracterización de las unidades se ha efectuado partiendo del predominio de elementos y energías, tal como propone la metodología presentada por Bolòs (1992), seguida por PérezChacón y colaboradores (2005) y aplicada recientemente con éxito en el Pirineo catalán (Bolòs y Gómez Ortiz, 2006).

Dicho método considera el paisaje como un complejo de elementos y energías susceptibles de combinarse en distinto grado, pero capaces de simplificarse según el predominio de componentes. Los paisajes, pues, pueden ser de tres tipos básicos, según dominancias abióticas, bióticas o antrópicas. Elementos y energías se definen según el papel que desarrollan en el conjunto, hecho que lleva a la aparición de componentes estructurantes, o de primer orden, y de componentes subordinados, o de segundo orden. Los componentes estructurantes tienen una participación igual o superior al 50\% del conjunto, mientras que los de segundo orden ofrecen una inferior al 50\% e igual o superior al 20\%; el método permite señalar la presencia minoritaria, pero significativa, de aquellas dominancias con una contribución inferior al 20\%. Así, la integración de parámetros se realiza de manera cuantitativa (según el significado del porcentaje respecto al total) y se matiza siguiendo un procedimiento cualitativo, donde participan el grado de detalle perseguido, el conocimiento del lugar y la pericia del responsable. La propuesta posibilita una representación minuciosa y sinóptica del ámbito estudiado, simbolizando los componentes abióticos con la letra F, los bióticos con la B y los antrópicos con la A. En el caso de predominio principal la participación respecto el conjunto se codifica con una letra mayúscula (A), en el caso de secundario con una letra minúscula (a) y en el caso de las participaciones inferiores a un $20 \%$ con una minúscula cursiva $(a)$. Se prevé la posibilidad de equivalencia de dominancias (interdependencia de componentes) a través de la representación mediante el uso de mayúsculas y paréntesis [(AB)]; el orden de simbolización se relaciona con la contribución respecto el total, si bien en el caso de equivalencia se priorizan las de carácter antrópico sobre las de carácter abiótico y éstas sobre las de carácter biótico (Bolòs y Serrano, 2008).

El paisaje, con todo, permite un acercamiento multiescalar, donde el predominio de componentes varía según el grado de detalle seguido. Es por ello que se ha realizado una subdivisión del territorio en distintos niveles de integración; de tal manera ha sido fácil establecer una correlación entre la precisión del estudio y la escala de trabajo. Se han establecido tres niveles jerárquicos que, al responder a una doble función de orden y clasificación, son también taxonómicos (López Fernández y López Fernández, 1985). El primer rango taxonómico se refiere a las unidades más detalladas, mientras que el último atiende a las unidades de carácter más general. Como fácilmente se puede percibir las unidades de paisaje y los rangos taxonómicos se encuentran íntimamente ligados. Las primeras toman sentido interno, es decir entre ellas, gracias a los rangos taxonómicos, que las clasifican y las jerarquizan, mientras que los segundos se constituyen y se relacionan mediante la delimitación previa de unidades. De la misma manera se colige la relación entre unidades 
de paisaje, rangos taxonómicos, escalas de trabajo y, a la postre, escalas de representación cartográfica.

En el proceso seguido ha tenido una participación especial el trabajo de campo. En un primer momento se realizó un reconocimiento inicial del territorio, que llevó al estudio pormenorizado de los elementos estructurantes y a la selección de los tres rangos taxonómicos. Seguidamente se efectúo una delimitación preliminar en gabinete de unidades de paisaje, a partir de la información recogida, el uso de documentos cartográficos, fotografías aéreas y un modelo digital de elevaciones. Más tarde se desarrolló un minucioso y exhaustivo trabajo de campo, ajustado a los tres niveles de estudio y con el objetivo de verificar, contrastar y, si acontecía, corregir las unidades previamente hilvanadas. Finalmente, se introdujeron los datos en un sistema de información geográfica, hecho que permitió construir una completa base de datos, así como generar distinta cartografía temática.

\section{RESULTADOS}

\subsection{Unidades de rango I}

El rango taxonómico I se compone por unidades de paisaje delimitadas con sumo detalle, ya que constituyen la base del estudio y de la taxonomía empleada. Las delimitaciones presentan validez a escala 1:10.000, que es la escala de trabajo recomendada en estudios de paisaje y ordenación del territorio (Flórez-Estrada et al., 1994; Hernández et al., 1999), y puntualmente contemplan subdivisiones con validez a escala 1:5.000, para espacios complejos o de difícil determinación. La precisión del estudio permite delimitar unidades de gran homogeneidad, que comparten características similares y, en consecuencia, poseen un funcionamiento parecido y una capacidad de acogida de usos análoga. La caracterización de las unidades se ha realizado según el predominio de elementos y energías, siguiendo una leyenda inspirada en el estudio de Bolòs y Gómez Ortiz (2006) para el Pirineo, y puntualmente matizada y ampliada en razón del lugar y la escala de trabajo, mayor en nuestro caso.

El objetivo de estas delimitaciones es destacar los aspectos estructurantes del paisaje a partir de un análisis detallado de elementos, dinámicas y energías. Su interés se encuentra en aportar una visión de elevado detalle, sintetizando información de manera minuciosa y con la mayor pulcritud posible. Al mismo tiempo el rango I toma especial interés por ser la base taxonómica del estudio y, por ende, soportar delimitaciones de mayor alcance espacial.

La codificación empleada se conforma por cuatro clases (predominio abiótico, biótico, antrópico y mixto) que se desgranan en distintas categorías con una participación desigual en el conjunto. Así las unidades de predominio abiótico se componen por tres categorías, las de predominio biótico por cuatro, las de predominio antrópico por siete y las de predominio mixto por cinco, desplegables todas ellas en distintas subcategorías (Tabla 1).

Atendiendo a unidades y subunidades se han delimitado 1.019 polígonos. Desde un punto de vista cuantitativo la categoría más abundante corresponde a bosques aciculifolios $(21,7 \%$ del total), con un repartimiento similar entre masas densas $\left(\mathrm{B}_{111}\right)$ y clareadas $\left(\mathrm{B}_{112}\right)$, y con una localización regular por todo el sector, si bien se encuentran de manera más abundante hacia el este y el centro. Las unidades con ocupación arbustiva afectan a casi un $11 \%$ de las delimitaciones, aunque con un repartimiento entre subcategorías muy dispar $\left(\mathrm{B}_{22}\right.$ poco más 
Tabla 1

UNIDADES DE PAISAJE DE RANGO I

\begin{tabular}{|c|c|c|c|}
\hline \multicolumn{4}{|c|}{ Unidades de predominio abiótico } \\
\hline $\mathbf{F}_{1}$ & roca compacta en pendiente acusada & & \\
\hline $\mathbf{F}_{2}$ & roca desnuda & & \\
\hline $\mathbf{F}_{5}$ & agua dulce & & \\
\hline \multicolumn{4}{|c|}{ Unidades de predominio biótico } \\
\hline \multirow[t]{11}{*}{$\mathbf{B}_{1}$} & bosque & & \\
\hline & $\mathbf{B}_{11}$ & bosque aciculifolio & \\
\hline & & $\mathbf{B}_{11}$ & bosque aciculifolio denso \\
\hline & & $\mathbf{B}_{12}$ & bosque aciculifolio claro \\
\hline & & $B_{112} f$ & $\begin{array}{l}\text { bosque aciculifolio claro en } \\
\text { pendiente }\end{array}$ \\
\hline & $\mathbf{B}_{12}$ & bosque caducifolio & \\
\hline & & $\mathbf{B}_{121}$ & bosque caducifolio denso \\
\hline & & $\mathbf{B}_{122}$ & bosque aciculifolio claro \\
\hline & $\mathbf{B}_{13}$ & bosque perennifolio mediterráneo & \\
\hline & & $\mathbf{B}_{131}$ & $\begin{array}{l}\text { bosque perennifolio } \\
\text { mediterráneo denso }\end{array}$ \\
\hline & & $\mathbf{B}_{132}$ & $\begin{array}{l}\text { bosque perennifolio } \\
\text { mediterráneo claro }\end{array}$ \\
\hline \multirow[t]{4}{*}{$\mathbf{B}_{2}$} & matorral & & \\
\hline & $\mathbf{B}_{21}$ & matorral denso & \\
\hline & $\mathbf{B}_{22}^{21}$ & matorral claro & \\
\hline & $\mathbf{B}_{22} \mathbf{f}$ & matorral claro en pendiente & \\
\hline $\mathbf{B}_{3}$ & herbazal, prado o pastizal de carácter natural & & \\
\hline BA & $\begin{array}{l}\text { vegetación degradada, antropizada o con } \\
\text { elementos antrópicos }\end{array}$ & & \\
\hline \multicolumn{4}{|c|}{ Unidades de predominio antrópico } \\
\hline \multirow[t]{4}{*}{$\mathbf{A}_{1}$} & espacio urbano compacto & & \\
\hline & $\mathbf{A}_{11}$ & $\begin{array}{l}\text { espacio urbano compacto con } \\
\text { edificaciones elevadas }\end{array}$ & \\
\hline & $A_{12}$ & $\begin{array}{l}\text { espacio urbano compacto con } \\
\text { edificaciones bajas }\end{array}$ & \\
\hline & $\mathbf{A}_{13}$ & $\begin{array}{l}\text { espacio urbano compacto con edifi- } \\
\text { caciones de altura diversa }\end{array}$ & \\
\hline \multirow[t]{2}{*}{$\mathbf{A}_{2}$} & espacio urbano laxo & & \\
\hline & $\mathrm{A}_{2} \mathbf{f}$ & $\begin{array}{l}\text { espacio urbano laxo en vertientes de } \\
\text { pendiente acusada }\end{array}$ & \\
\hline $\mathbf{A}_{3}$ & complejo de servicios & & \\
\hline $\mathrm{A}_{4}$ & infraestructuras & & \\
\hline $\mathrm{A}_{5}$ & complejo industrial o logístico & & \\
\hline $\mathrm{A}_{6}$ & complejo deportivo & & \\
\hline \multirow[t]{2}{*}{$\mathbf{A F}$} & minería & & \\
\hline & $\mathbf{A F}$ & cantera, extracción de áridos & \\
\hline \multicolumn{4}{|c|}{ Unidades de predominio mixto } \\
\hline$\left(\mathrm{AF}_{5}\right)$ & pantano & & \\
\hline \multirow[t]{6}{*}{$(\mathrm{AB})$} & zona de cultivo, explotación agraria tradicional & & \\
\hline & $\left(\mathrm{AB}_{1}\right)$ & cultivo arbóreo de secano & \\
\hline & $\left(\mathrm{AB}_{2}\right)$ & cultivo arbustivo de secano & \\
\hline & $\left(\mathrm{AB}_{1}\right) \mathbf{f}_{5}$ & cultivo arbóreo de regadío & \\
\hline & $\left(\mathrm{AB}_{123}\right) \mathbf{f}_{5}$ & cultivo herbáceo de regadío, huerta & \\
\hline & $\mathbf{A}_{3}(\mathbf{A B}) \mathbf{f}_{5}$ & campo de golf, jardín & \\
\hline$(\mathbf{F}, \mathbf{A})$ & mina abandonada & & \\
\hline (Ba) & zona de cultivo abandonada & & \\
\hline (Ba)f & $\begin{array}{l}\text { zona de cultivo abandonada en bancal o en } \\
\text { vertiente con pendiente acusada }\end{array}$ & & \\
\hline
\end{tabular}


de un $5 \% ; \mathrm{B}_{22} \mathrm{f}$, un $2,7 \%$ ). Siguen por orden de abundancia las unidades dedicadas a cultivos de secano y urbanizaciones extensivas en ladera (en ambos casos con una participación del $10,7 \%$ ). Un 6,5\% de las delimitaciones se refiere a acantilados, un 5,6\% a superficies urbanizadas de baja densidad y un 5,1\% a matorral denso. Un número muy considerable de categorías y subcategorías (articuladas por 15 categorías principales) presentan participaciones inferiores al 5\% del total, hecho que debería entenderse como una expresión de la heterogeneidad del paisaje y, hasta cierto punto, también de su fragmentación.

Las unidades dominadas por elementos bióticos significan un 42,5\% del conjunto, y se organizan en seis grandes categorías con una presencia significativa en el sector central y oriental de Muntayes d'Ordal. Las unidades dominadas por elementos antrópicos se refieren a un $32,4 \%$ del total, con una distribución muy irregular por todo el sector. De las siete categorías principales diferenciadas, la de mayor implantación (con 94 delimitaciones) atiende a espacios urbanos de carácter extensivo con una presencia de elementos bióticos remarcable, y donde el relieve toma un peso decisivo en la configuración de la unidad; su distribución se concentra en la parte central de Muntanyes d'Ordal. Las unidades dominadas por elementos abióticos se concretan en un 7,8\% del área de estudio. La categoría más representativa se $\left(A B_{1}\right),\left(A B_{2}\right),\left(A B_{1}\right) f_{5},\left(A B_{123}\right) f_{5} ; 13-A_{3}(A B) f_{5} ; 14-A_{1}, A_{11}, A_{12}, A_{13} ; 15-A_{2}, A_{2} f ; 16-A_{3} ; 17-A_{4}, A_{5}, A_{6} ; 18-A F_{2}$

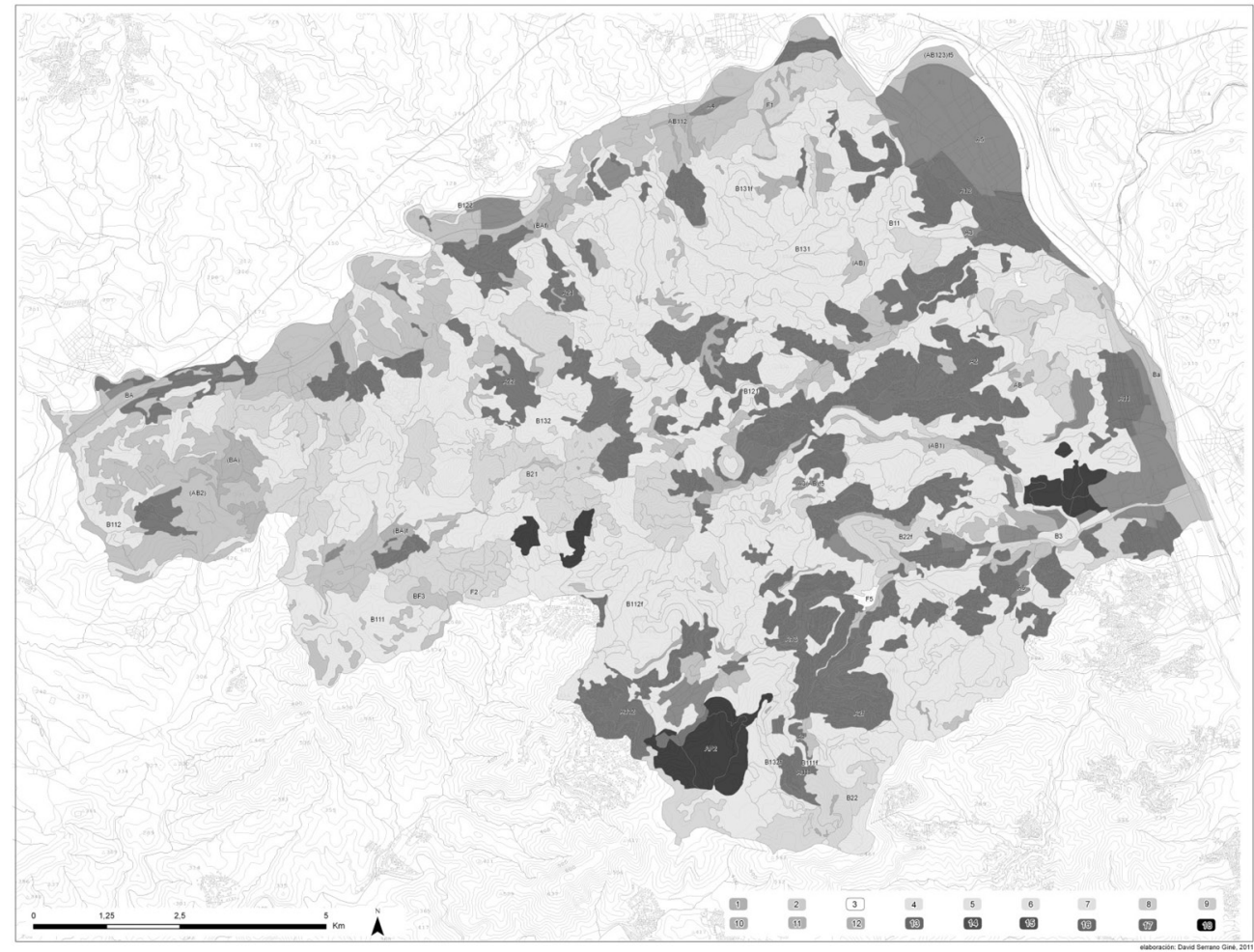


refiere a unidades estructuradas por la presencia de agua dulce, y con una corología asociada a los cauces de los ríos Anoia y Llobregat. Siguen de cerca las unidades formadas por acantilados y cortados rocosos de distinto tipo; su localización se da principalmente en el flanco este del sector, sobre roquedo calizo y, en segundo lugar, triásico. Las unidades con equidad de energías se encuentran representadas en más de un $90 \%$ por la categoría agraria, que comprende tres subcategorías con una distribución bastante irregular pero principalmente excéntrica (Fig. 3).

\subsection{Unidades de rango II}

El rango taxonómico II se constituye por unidades de paisaje con validez a escala 1:20.000. Su definición y caracterización se ha realizado mediante la generalización de unidades de rango I, atendiendo a los ya citados criterios de homogeneidad, dinámica y funcionalidad, a los que se añade el de territorialidad. En el proceso de agregación de delimitaciones se han considerado por igual criterios de unión y de integración de categorías de rango I. Las unidades de rango II se constituyen a partir de la delimitación de entidades de carácter biótico y antrópico, principalmente, según condicionantes morfolitológicos y, en menor medida, perceptivos. La caracterización final de las unidades se ha realizado de acuerdo al dominio o, si acontecía, el predominio de elementos y energías, partiendo siempre de las delimitaciones de rango I.

En este proceso se ha empleado un método cualitativo, que considera individualmente cada categoría de la clasificación y la favorece o, por el contrario, la subordina, según su participación real en el paisaje (Tabla 2 y 3). El objetivo de estas delimitaciones es destacar los aspectos de mayor peso en el paisaje a partir de una aproximación preliminar y principalmente fisiognómica. Su interés se encuentra en aportar una visión de semi-detalle, ofreciendo una aproximación más general que la de las unidades de rango I pero más detallada que las de rango III; por tanto cumple el propósito de servir de puente entre las delimitaciones más detalladas y las más generales.

La generalización de las unidades de rango I a unidades de rango II se ha realizado de manera cualitativa, ya que una simplificación estrictamente cuantitativa distorsionaba fuertemente los resultados finales. El procedimiento seguido parte de combinar tres aspectos distintos:

a) Categorías de rango I de más frecuencia y con unidades de mayor alcance superficial

b) Existencia de otras categorías de rango I de probada importancia pero menor peso en número y superficie de unidades

c) Número total de delimitaciones y carácter general de la unidad, según criterios de homogeneidad, dinámica, funcionalidad y percepción

Conviene aclarar, no obstante, que este método no se corresponde a una simple agregación de unidades básicas, sino a una valoración individualizada, cualitativa y detallada de cada unidad de paisaje y de su contexto inmediato, según el predominio de elementos y energías y en función de su participación en el conjunto a escala 1:20.000. Este planteamiento, finalmente, ha permitido pasar de más de mil delimitaciones realizadas con gran detalle (las correspondientes al rango I) a 74 delimitaciones de semi-detalle expresadas en tres clases (predomino biótico, predominio antrópico y predominio mixto) y ocho categorías (predo- 


\begin{tabular}{|c|c|c|c|c|c|c|c|c|c|c|c|c|c|c|c|c|c|}
\hline 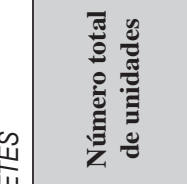 & 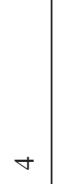 & $=$ & \pm & $\Xi$ & $\simeq$ & $\hat{m}$ & P & సे & $\tilde{\sim}$ & $=$ & \pm & $r$ & $\sigma$ & $N$ & 0 & 0 & $\cong$ \\
\hline 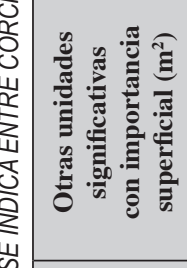 & $\begin{array}{c}\Xi \\
\infty^{\Xi}\end{array}$ & 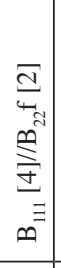 & 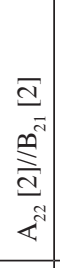 & 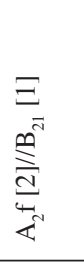 & $\underset{\mathbb{\alpha}^{m}}{\bar{m}}$ & $\underset{\infty^{\cong}}{\stackrel{\Xi}{\Xi}}$ & 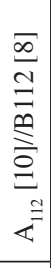 & $\begin{array}{c}\Xi \\
\infty^{\overline{2}}\end{array}$ & $\begin{array}{c}\bar{m} \\
\equiv \\
\infty^{\prime}\end{array}$ & $\begin{array}{c}\bar{\Xi} \\
\infty^{\beth}\end{array}$ & $\begin{array}{l}\bar{m} \\
\underset{\mathbb{*}}{*}\end{array}$ & $\begin{array}{c}\Xi \\
\equiv \\
\infty^{\prime}\end{array}$ & $\begin{array}{c}\Xi \\
\Xi \\
\equiv\end{array}$ & 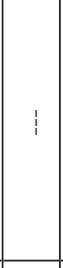 & 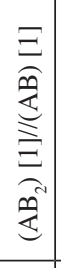 & $\begin{array}{c}\bar{m} \\
\mathbb{4}^{2}\end{array}$ & 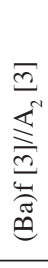 \\
\hline 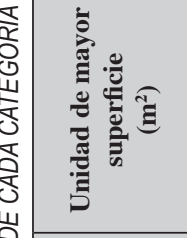 & $\begin{array}{c}\Xi \\
\cong \\
n^{\Xi}\end{array}$ & $\begin{array}{l}\bar{m} \\
\varangle\end{array}$ & $\begin{array}{l}\Xi \\
\infty^{2} \\
\end{array}$ & $\begin{array}{l}\Xi \\
\infty^{\prime}\end{array}$ & $\begin{array}{l}\Sigma \\
\mathbb{<}^{\prime \prime}\end{array}$ & $\frac{\Sigma}{\infty}$ & 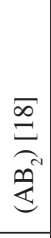 & $\begin{array}{c}\Xi \\
\equiv \\
\equiv\end{array}$ & $\begin{array}{l}\infty \\
\varangle\end{array}$ & $\begin{array}{l}\infty \\
\infty \\
x^{N}\end{array}$ & $\begin{array}{c}\bar{a} \\
\equiv \\
\infty^{\prime}\end{array}$ & $\begin{array}{l}\Sigma \\
\infty^{-}\end{array}$ & $\begin{array}{c}\Xi \\
\equiv \\
\infty^{\Xi}\end{array}$ & $\begin{array}{c}\bar{\Xi} \\
\infty^{-}\end{array}$ & $\frac{\Xi}{\mathbb{Z}^{N}}$ & $\begin{array}{c}\bar{m} \\
\infty^{\cong}\end{array}$ & $\frac{\sqrt[\pi]{2}}{\sqrt[\infty]{2}}$ \\
\hline 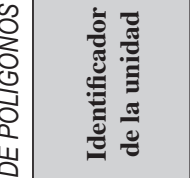 & $\stackrel{\infty}{m}$ & ले & 우 & $\vec{\gamma}$ & F & $\stackrel{\vartheta}{\vartheta}$ & $\forall$ & $\stackrel{n}{\forall}$ & + & 于 & $\stackrel{\infty}{+}$ & $\stackrel{g}{q}$ & in & $\bar{n}$ & in & $\tilde{n}$ & in \\
\hline 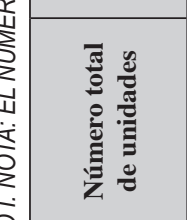 & $n$ & $=$ & $\stackrel{\infty}{-}$ & $=$ & $\infty$ & ป & $\Xi$ & $\simeq$ & $=$ & $\nabla$ & $\Xi$ & $\hat{\imath}$ & $\simeq$ & 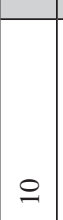 & 0 & $N$ & $\vec{\lambda}$ \\
\hline 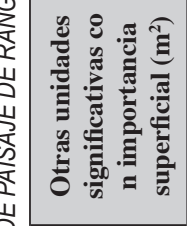 & $\begin{array}{l}\Xi \\
\varangle^{2}\end{array}$ & 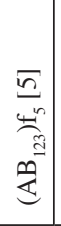 & $\begin{array}{c}\Xi \\
\Xi \\
\frac{n^{\Xi}}{\sigma} \\
\frac{\sigma}{\omega^{-}}\end{array}$ & 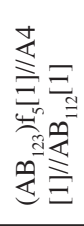 & 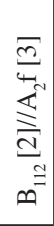 & 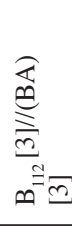 & $\begin{array}{l}\bar{\Xi} \\
\stackrel{\vec{D}}{\infty}\end{array}$ & $\begin{array}{l}\bar{a} \\
\overleftrightarrow{a} \\
\stackrel{a}{a} \\
\dot{m}^{n}\end{array}$ & $\begin{array}{l}\bar{\Xi} \\
\infty^{m}\end{array}$ & $\begin{array}{c}\Xi \\
\infty^{\Xi}\end{array}$ & 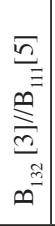 & 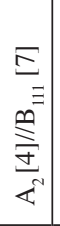 & $\begin{array}{l}\Xi \\
\varangle\end{array}$ & $\begin{array}{c}\Xi \\
\Xi \\
\equiv\end{array}$ & $\begin{array}{c}\bar{\Xi} \\
\equiv\end{array}$ & $\begin{array}{l}\Xi \\
\infty^{\Xi}\end{array}$ & $\stackrel{\Xi}{\infty^{\prime}}$ \\
\hline 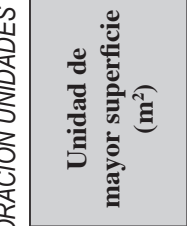 & 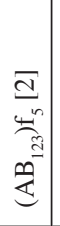 & $\begin{array}{l}\Sigma \\
\ll^{n}\end{array}$ & $\begin{array}{c}\bar{a} \\
\infty^{2}\end{array}$ & $\frac{\sqrt{6}}{\sqrt[0]{\Xi}}$ & $\begin{array}{c}\bar{\Xi} \\
\infty^{\Xi}\end{array}$ & $\begin{array}{l}\underset{\nabla}{\Xi} \\
q^{N}\end{array}$ & $\begin{array}{c}\Xi \\
\equiv \\
\equiv\end{array}$ & $\begin{array}{l}\Xi \\
\infty^{-}\end{array}$ & $\begin{array}{c}\bar{n} \\
\equiv \\
\infty^{\prime}\end{array}$ & $\begin{array}{l}\bar{\Xi} \\
\mathbb{Z}^{\prime}\end{array}$ & $\frac{\bar{n}}{\bar{m}}$ & $\begin{array}{l}\sqrt{2} \\
n^{2}\end{array}$ & $\begin{array}{l}\bar{a} \\
\infty^{N}\end{array}$ & $\left|\begin{array}{c}\bar{\sigma} \\
\cong \\
\emptyset\end{array}\right|$ & $\begin{array}{c}\underset{\Xi}{\Xi} \\
\infty^{\beth}\end{array}$ & $\begin{array}{l}\Xi \\
\varangle\end{array}$ & 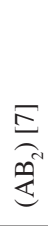 \\
\hline 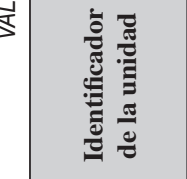 & - & $N$ & $m$ & $\nabla$ & $n$ & 0 & $r$ & $\infty$ & $a$ & $\bumpeq$ & $=$ & $\simeq$ & 3 & \pm & $\because$ & $\stackrel{0}{-}$ & I \\
\hline
\end{tabular}




\begin{tabular}{|c|c|c|c|c|c|c|c|c|c|c|c|c|c|c|c|c|c|c|c|}
\hline$\approx$ & 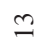 & $n$ & 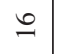 & ¿ & $a$ & \pm & $\vec{\sim}$ & $\tilde{\lambda}$ & $\stackrel{0}{-}$ & 6 & $\simeq$ & 6 & $\gtrsim$ & $\tilde{\imath}$ & $N$ & 6 & $\infty$ & ส & $\simeq$ \\
\hline $\begin{array}{l}\Xi \\
\Xi \\
\stackrel{n^{\prime}}{\Xi} \\
\frac{m}{m} \\
\frac{m}{\infty}\end{array}$ & $\begin{array}{l}\bar{d} \\
\frac{L^{N}}{\alpha}\end{array}$ & $\begin{array}{l}\bar{\Xi} \\
\underset{\varpi}{\Xi} \\
\infty\end{array}$ & $\begin{array}{c}\bar{m} \\
\underset{\Xi}{a} \\
m \\
\equiv \\
\equiv\end{array}$ & 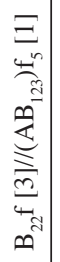 & 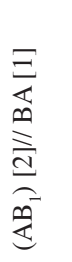 & 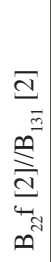 & $\begin{array}{c}\bar{m} \\
\stackrel{m}{=} \\
\infty^{\prime}\end{array}$ & 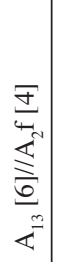 & 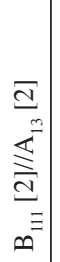 & $\underset{\underset{C}{\mathbb{C}}}{\bar{d}}$ & 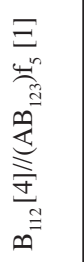 & $\underset{\mathbb{Z}}{\mathbb{Z}}$ & 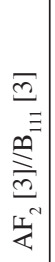 & $\begin{array}{c}\sigma \\
\infty^{\Xi}\end{array}$ & $\begin{array}{c}\Xi \\
\equiv \\
\infty^{\prime}\end{array}$ & $\begin{array}{l}\Xi \\
\Xi \\
\Xi\end{array}$ & $\left|\begin{array}{c}\Xi \\
\Xi \\
\stackrel{\Xi}{\Xi} \\
\Xi \\
\emptyset^{\mathrm{J}}\end{array}\right|$ & 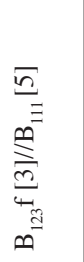 & $\begin{array}{c}\Xi \\
\Xi \\
\stackrel{n}{\Xi} \\
\Xi \\
\infty^{\Xi}\end{array}$ \\
\hline $\begin{array}{l}\underset{\infty^{N}}{\Xi} \\
\underset{n^{2}}{ \pm}\end{array}$ & $\begin{array}{c}\bar{\Omega} \\
\infty^{\cong}\end{array}$ & $\begin{array}{c}\bar{\beth} \\
\infty^{\cong}\end{array}$ & $\begin{array}{l}\sqrt{\Omega} \\
n^{\beth}\end{array}$ & $\begin{array}{l}\Xi \\
\Xi \\
\mathbb{E}\end{array}$ & $\frac{\bar{m}}{m^{-}}$ & $\underset{\psi}{E}$ & $\underset{\infty}{\Xi} \underset{\infty}{\Xi}$ & $\begin{array}{l}\underset{\Xi}{n^{2}} \\
\mid\end{array}$ & $\begin{array}{l}\bar{\sigma} \\
\Sigma^{N}\end{array}$ & $\underset{\infty}{\bar{\Xi}}$ & 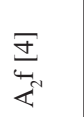 & $\begin{array}{c}\bar{\omega} \\
\equiv \\
\equiv\end{array}$ & $\begin{array}{l}\underset{\sigma}{\sigma} \\
\underset{<}{*}\end{array}$ & $\begin{array}{c}\Xi \\
\Xi \\
\equiv\end{array}$ & $\begin{array}{c}\Xi \\
\infty^{\Xi}\end{array}$ & $\begin{array}{l}\bar{n} \\
\vec{E}^{\prime}\end{array}$ & $\left|\begin{array}{l}\bar{\nu} \\
\mathbb{L}^{N}\end{array}\right|$ & $\underset{\infty^{\Xi}}{\Xi}$ & $\begin{array}{l}\bar{a} \\
n^{2}\end{array}$ \\
\hline$n$ & in & in & $\stackrel{\infty}{n}$ & in & 8 & $\vec{\sigma}$ & ช్ & $\hat{6}$ & t & 6 & 8 & $\hat{\sigma}$ & $\infty$ & 8) & $尺$ & $\nabla$ & $\approx$ & $\approx$ & 只 \\
\hline$\simeq$ & $=$ & $n$ & $\stackrel{0}{0}$ & $\stackrel{\infty}{=}$ & $\simeq$ & $n$ & $r$ & $\stackrel{+}{d}$ & $\stackrel{ }{\circ}$ & $=$ & $\stackrel{\infty}{-}$ & \pm & $\infty$ & $\infty$ & $r$ & $a$ & $=$ & $\ddot{\lambda}$ & $\vec{\sim}$ \\
\hline $\begin{array}{c}\Xi \\
\equiv \\
\infty^{\Xi}\end{array}$ & $\underset{\infty^{m}}{\Xi}$ & $\begin{array}{c}\bar{\Xi} \\
\infty^{\beth}\end{array}$ & $\begin{array}{c}\Xi \\
\infty^{\Xi}\end{array}$ & $\underset{\varepsilon^{m}}{\Xi}$ & 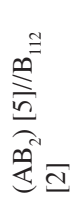 & 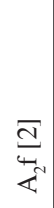 & $\begin{array}{c}\bar{\Xi} \\
\infty^{\Xi}\end{array}$ & 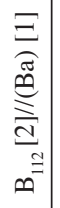 & 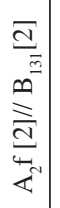 & 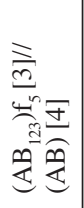 & 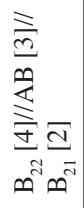 & $\underset{\infty^{2}}{\Xi}$ & $\begin{array}{l}\bar{a} \\
= \\
\frac{s}{a} \\
\frac{m}{d} \\
\frac{w}{4}\end{array}$ & $\begin{array}{l}\bar{d} \\
\stackrel{\sim}{\Xi} \\
\end{array}$ & 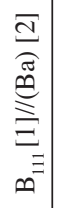 & $\underset{\Xi}{\Xi}$ & $\underset{\infty}{\stackrel{\bar{g}}{\Xi}}$ & 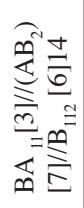 & 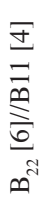 \\
\hline $\begin{array}{l}\bar{n} \\
\infty^{\cong}\end{array}$ & $\frac{\sqrt{n}}{\infty}$ & 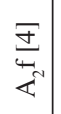 & $\frac{\pi}{\pi}$ & 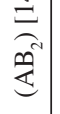 & $\begin{array}{l}\bar{\Xi} \\
\mathbb{4}^{2}\end{array}$ & $\begin{array}{l}\Xi \\
\infty^{7}\end{array}$ & $\begin{array}{c}\bar{\omega} \\
\equiv \\
\equiv\end{array}$ & $\begin{array}{l}\infty \\
\underset{\psi}{\infty} \\
\mathbb{\psi}^{\prime}\end{array}$ & $\begin{array}{l}\bar{\Xi} \\
\bar{\infty}\end{array}$ & $\underset{\equiv}{\Xi}$ & $\underset{\Xi}{\Xi}$ & $\frac{\sqrt{n}}{\ll^{n}}$ & $\begin{array}{l}\bar{\sigma} \\
\mathbb{4}^{N}\end{array}$ & $\frac{\sqrt{n}}{n^{-}}$ & $\begin{array}{c}\bar{\omega} \\
\infty^{\cong}\end{array}$ & $\frac{\sigma}{a^{-}}$ & $\frac{\sigma}{\mathbb{R}^{n}}$ & $\underset{\Psi^{N}}{\Xi}$ & $\begin{array}{l}\bar{\sigma} \\
\infty^{\overline{1}}\end{array}$ \\
\hline$\cong$ & 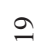 & సి & $\vec{\sim}$ & $\approx$ & $\hat{\lambda}$ & $\stackrel{ \pm}{\sim}$ & $\ddot{\sim}$ & $\stackrel{\sim}{\sim}$ & $\hat{\imath}$ & $\stackrel{\infty}{\sim}$ & ते & ల్ల & $\vec{m}$ & กี & $\hat{m}$ & ఉా & $m$ & i & $\hat{n}$ \\
\hline
\end{tabular}


Tabla 3

UNIDADES DE PAISAJE DE RANGO /I

\begin{tabular}{|c|c|c|c|c|c|c|c|}
\hline $\begin{array}{l}\text { Identificador } \\
\text { de la unidad }\end{array}$ & $\begin{array}{c}\text { Clasificación } \\
\text { final }\end{array}$ & $\begin{array}{l}\text { Identificador } \\
\text { de la unidad }\end{array}$ & $\begin{array}{c}\text { Clasificación } \\
\text { final }\end{array}$ & $\begin{array}{l}\text { Identificador } \\
\text { de la unidad }\end{array}$ & $\begin{array}{c}\text { Clasificación } \\
\text { final }\end{array}$ & $\begin{array}{l}\text { Identificador } \\
\text { de la unidad }\end{array}$ & $\begin{array}{c}\text { Clasificación } \\
\text { final }\end{array}$ \\
\hline 1 & $(\mathrm{AB})$ & 20 & $\mathrm{~B}_{1}$ & 39 & $\mathrm{~A}_{1}$ & 58 & $A_{1}$ \\
\hline 2 & BA & 21 & $A_{1}$ & 40 & $\mathrm{~B}_{1}$ & 59 & $\mathrm{~B}_{2}$ \\
\hline 3 & $\mathrm{~B}_{2}$ & 22 & $(\mathrm{AB})$ & 41 & $\mathrm{BA}$ & 60 & $\mathrm{~B}_{1}$ \\
\hline 4 & $(\mathrm{AB})$ & 23 & $\mathrm{~B}_{1}$ & 42 & $\mathrm{~A}_{2}$ & 61 & $\mathrm{~B}_{1}$ \\
\hline 5 & $\mathrm{~B}_{1}$ & 24 & $\mathrm{~B}_{2}$ & 43 & $\mathrm{~B}_{1}$ & 62 & $\mathrm{~B}_{1}$ \\
\hline 6 & $\mathrm{BA}$ & 25 & $\mathrm{~B}_{1}$ & 44 & $\mathrm{~B}_{1}$ & 63 & $\mathrm{~A}_{1}$ \\
\hline 7 & $\mathrm{~B}_{1}$ & 26 & $\mathrm{~B}_{1}$ & 45 & $\mathrm{~B}_{2}$ & 64 & $\mathrm{~B}_{1}$ \\
\hline 8 & $\mathrm{~B}_{1}$ & 27 & $\mathrm{~B}_{1}$ & 46 & $\mathrm{~A}_{1}$ & 65 & $\mathrm{~B}_{1}$ \\
\hline 9 & $\mathrm{~B}_{1}$ & 28 & $\mathrm{~B}_{1}$ & 47 & $\mathrm{AF}_{2}$ & 66 & $\mathrm{~A}_{2}$ \\
\hline 10 & $\mathrm{~B}_{1}$ & 29 & $\mathrm{~B}_{1}$ & 48 & $\mathrm{~B}_{1}$ & 67 & $\mathrm{~A}_{2}$ \\
\hline 11 & $\mathrm{~B}_{1}$ & 30 & $\mathrm{~A}_{5}$ & 49 & $\mathrm{~B}_{1}$ & 68 & $\mathrm{~B}_{1}$ \\
\hline 12 & $\mathrm{~B}_{2}$ & 31 & $\mathrm{~A}_{2}$ & 50 & $\mathrm{~B}_{1}$ & 69 & $\mathrm{~B}_{1}$ \\
\hline 13 & $\mathrm{~B}_{2}$ & 32 & $\mathrm{~B}_{1}$ & 51 & $\mathrm{~B}_{1}$ & 70 & $\mathrm{~B}_{1}$ \\
\hline 14 & $\mathrm{~B}_{1}$ & 33 & $\mathrm{~B}_{1}$ & 52 & $\mathrm{~A}_{2}$ & 71 & $\mathrm{~A}_{2}$ \\
\hline 15 & $\mathrm{~B}_{1}$ & 34 & $\mathrm{~B}_{1}$ & 53 & $\mathrm{~B}_{1}$ & 72 & $\mathrm{~A}_{2}$ \\
\hline 16 & $\mathrm{~A}_{1}$ & 35 & $\mathrm{~A}_{2}$ & 54 & $(\mathrm{AB})$ & 73 & $\mathrm{~B}_{1}$ \\
\hline 17 & $(\mathrm{AB})$ & 36 & $\mathrm{~A}_{2}$ & 55 & $\mathrm{~B}_{2}$ & 74 & $\mathrm{~B}_{1}$ \\
\hline 18 & $\mathrm{~B}_{1}$ & 37 & $\mathrm{~B}_{2}$ & 56 & $\mathrm{~B}_{1}$ & & \\
\hline 19 & $\mathrm{~B}_{1}$ & 38 & $\mathrm{~B}_{1}$ & 57 & $\mathrm{~B}_{1}$ & & \\
\hline
\end{tabular}

minio de bosque; predominio de monte; predominio de agricultura o explotaciones agrarias tradicionales; predominio de agricultura, vegetación degradada o con un grado elevado de antropización; predominio de núcleo urbano compacto; predominio de núcleo urbano laxo; predominio de complejos industriales o logísticos; predominio de canteras o extracciones de áridos).

Las delimitaciones con valor forestal son netamente mayoritarias, alcanzando un $47 \%$ de las teselas establecidas, repartidas en cerca de cuarenta unidades de rango II y concentradas principalmente en el sector central de Muntanyes d'Ordal. Se trata de formaciones forestales aciculifolias densas, con una pequeña participación de bosques perennifolios mediterráneos que se aclaran progresivamente hacia el sur y el oeste. Por el contrario las formaciones arbustivas son más bien escasas (ocho unidades con una participación del 11\% del territorio) y ofrecen una corología bastante excéntrica; acostumbran a localizarse en los límites de las formaciones arboladas y en transición con otras unidades. Los espacios con equidad de energías son relativamente abundantes (15\% de la superficie total) y responden mayormente a sectores destinados a cultivos con una distribución claramente centrífuga.

Con todo, el rasgo principal de Muntayes d'Ordal no viene de la mano de las formaciones forestales o los espacios agrarios, sino de las unidades de dominio antrópico. Entre éstas sobresalen de manera particular las urbanizaciones de baja densidad, principalmente en laderas de poca o mucha pendiente, pero también sobre topografías más llanas. Se trata 


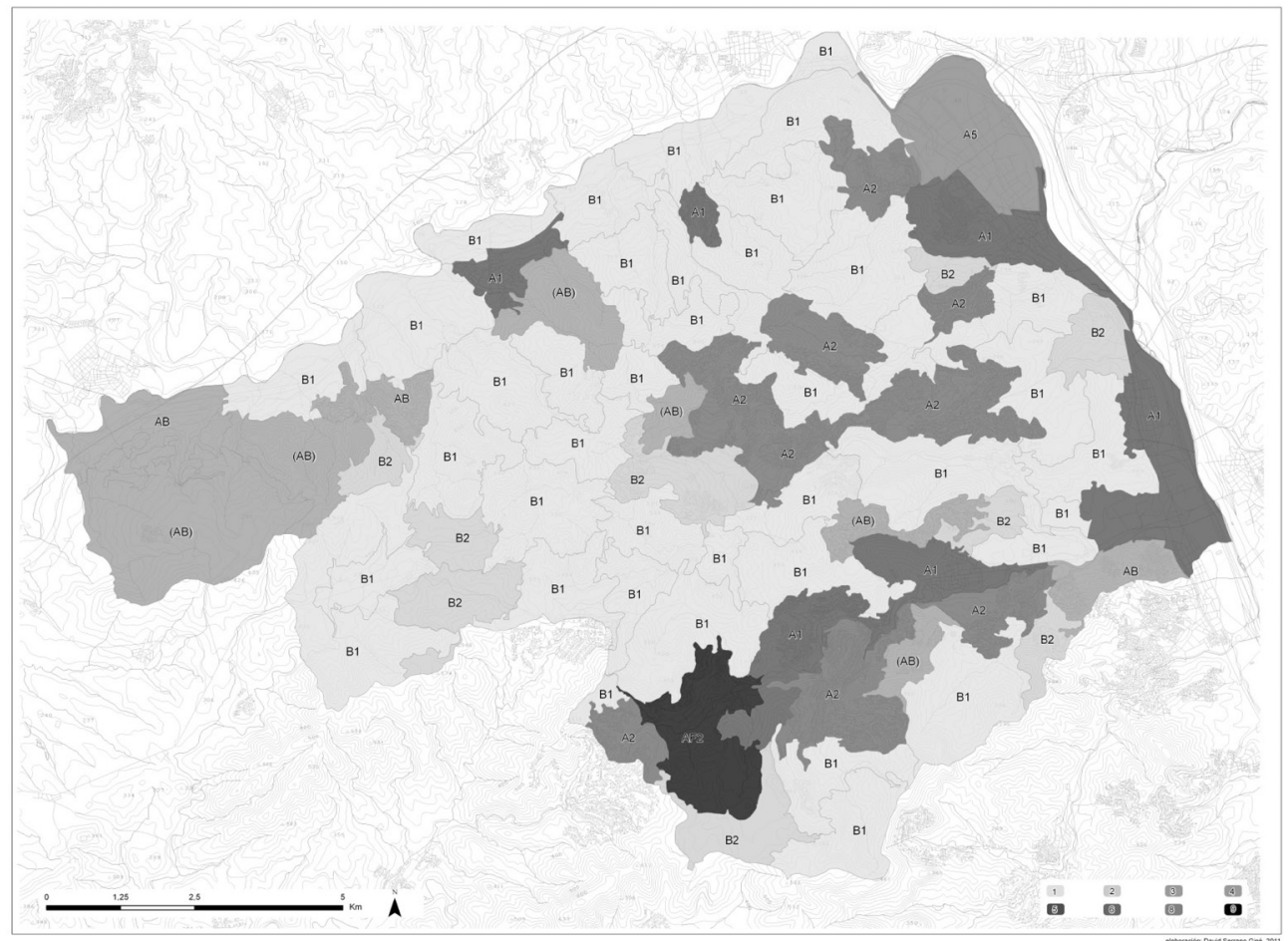

de una docena de delimitaciones con una distribución irregular y, a menudo, polarizada. Así resulta fácil notar tres grandes ejes longitudinales que, de este a oeste, segmentan y articulan al mismo tiempo el área de estudio. Esta huella fisiognómica se termina perfilando con las unidades urbanas de carácter compacto, fácilmente individualizables por su heterogeneidad volumétrica y dispersión de formas. Esta categoría se reparte en seis delimitaciones bastante agrupadas, que comportan un $9 \%$ del territorio. Finalmente, y para completar esta diversidad, conviene indicar los espacios de dominio industrial y logístico; se estructuran en dos delimitaciones marginales pero de gran dimensión, con un peso territorial significativo (6\%) y una percepción visual indiscutible (Fig. 4).

\subsection{Unidades de rango III}

El rango taxonómico III se forma a partir de unidades de paisaje delimitadas bajo criterios de carácter territorial, posee un valor indudablemente geográfico y validez a escala 1:25.000. En su caracterización se ha adoptado una perspectiva holística, que sintetiza las unidades de rango II y las matiza con los valores territoriales que mejor las definen. En el proceso de generalización se han respetado los valores sistémicos aplicados a las unidades de rango inferior y, también, se han considerado las afinidades y los rasgos particulares propios 
del lugar. Las corografías resultantes enlazan la idea de genius loci con el planteamiento global de los Estudios integrados, tal y como postula la obra clásica de Georges Bertrand. Es por ello que las delimitaciones de este rango reúnen, por una parte, los valores sistémicos de homogeneidad, dinámica y funcionalidad y, por otra parte, los valores inherentes al historicismo geográfico. Las delimitaciones resultantes son unidades con valor fisiognómico y sistémico, de indudable significado geográfico.

Se han distinguido 14 unidades de rango III. Su caracterización se ha realizado siguiendo los postulados clásicos de estructura, función y génesis; su denominación se ha realizado de acuerdo a sus características definitorias, en relación en el contexto territorial donde se encuentran, la escala de trabajo y el alcance temporal del estudio. De poniente a levante las unidades establecidas son: 1. Concentración urbana e industrial sobre llano aluvial y piedemonte, 2. Viñedos y piedemonte suave, 3. Bosque perennifolio mediterráneo en ladera de sustrato silíceo, 4. Bosque aciculifolio mediterráneo en ladera de sustrato calizo y cierta tendencia continental, 5. Urbanizaciones extensivas y bosque aciculifolio mediterráneo en ladera de pendiente acusada, 6. Monte mediterráneo y urbanizaciones extensivas sobre relieve en cuesta y piedemonte asociado, 7. Industria y viviendas sobre llano aluvial y ladera de pendiente suave, 8. Ladera de pendiente suave con cultivos arbustivos de secano, 9. Bosque aciculifolio y monte mediterráneo sobre sustrato básico en ladera de pendiente acusada, 10. Bosque aciculifolio mediterráneo clareado y urbanizaciones extensivas sobre sustrato básico en ladera de pendiente acusada, 11. Cultivo arbustivo de secano en ladera de pendiente suave, 12. Bosque aciculifolio y perennifolio sobre sustrato paleozoico y exposición umbría en ladera de pendiente acusada, 13. Bosque aciculifolio mediterráneo en ladera suave sobre sustrato triásico, y 14. Monte esclerófilo mediterráneo en rellano calizo y tendencia mediterránea.

La unidad de mayor alcance territorial es Bosque aciculifolio mediterráneo clareado y urbanizaciones extensivas sobre sustrato básico en ladera de pendiente acusada, con una ocupación cercana al $20 \%$ del conjunto, y seguida a distancia de Bosque aciculifolio y monte mediterráneo sobre sustrato básico en ladera de pendiente acusada, con una representación cercana al $15 \%$. Las unidades Bosque perennifolio mediterráneo en ladera de sustrato silíceo y Urbanizaciones extensivas y bosque aciculifolio mediterráneo en ladera de pendiente acusada, comportan poco más del 11 y el $12 \%$ del área de estudio, mientras que las diez unidades restantes ofrecen una participación territorial marcadamente menor. No obstante, desde un punto de vista cualitativo la unidad con mayor peso fisiognófico y perceptual es, sin duda, Urbanizaciones extensivas y bosque aciculifolio mediterráneo en ladera de pendiente acusada (a pesar de ofrecer una contribución territorial cercana al 12\% del conjunto). Otras unidades con una impronta visual y un peso en el imaginario colectivo indiscutible son Concentración urbana e industrial sobre llano aluvial y piedemonte, Industria y viviendas sobre llano aluvial y ladera de pendiente suave y Monte mediterráneo y urbanizaciones extensivas sobre relieve en cuesta y piedemonte asociado. Resulta curioso observar como determinadas unidades, como por ejemplo Ladera de pendiente suave con cultivos arbustivos de secano, no terminan de ser percibidas por la población local como entidades plenamente integrantes del conjunto, sino más bien como unidades marginales sin una personalidad definida. Quizás esto se deba, precisamente, a no corresponderse con la percepción más difundida de Muntanyes d'Ordal y, con ello, con el carácter del lugar (Fig. 5). 


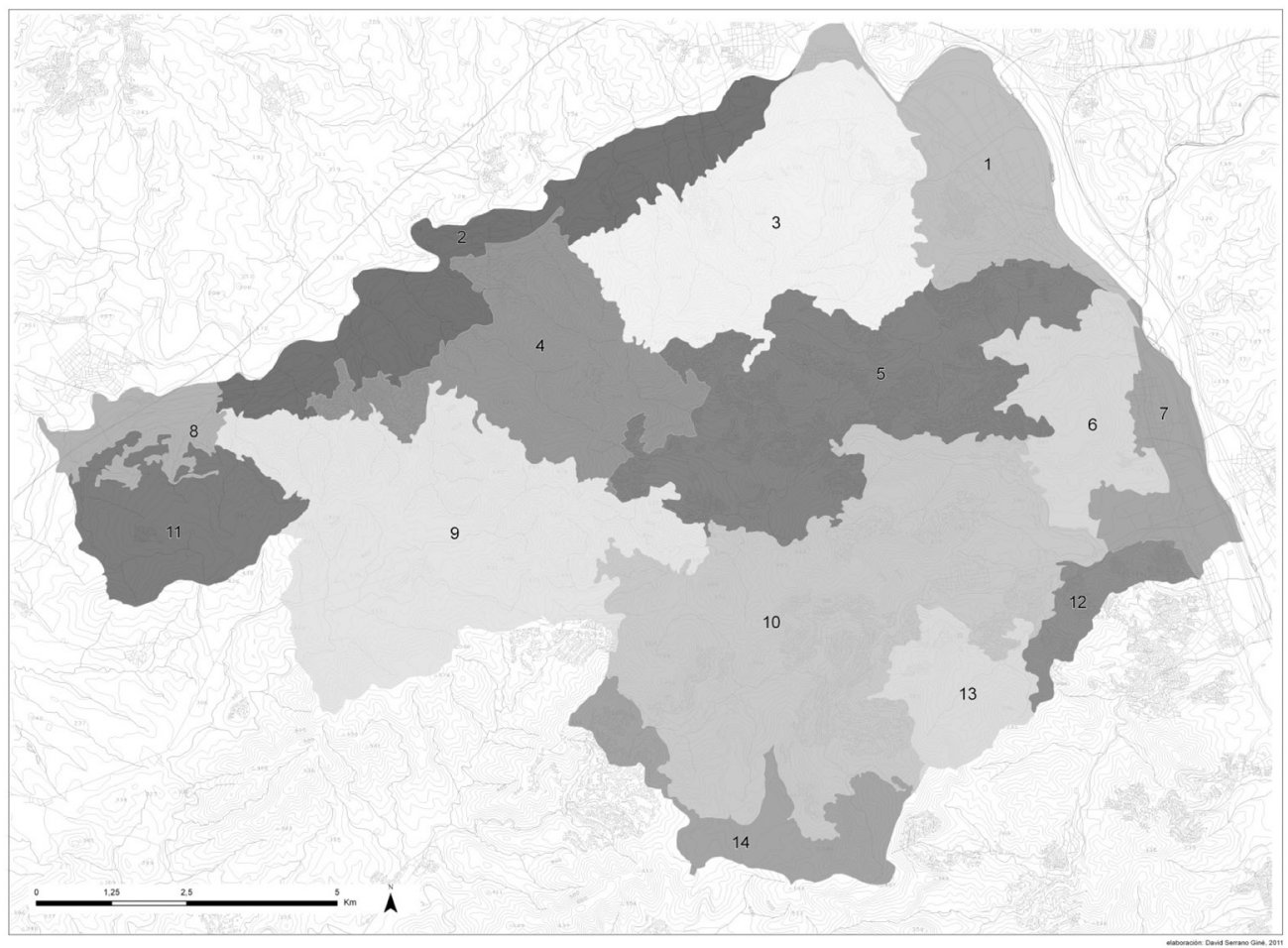

\section{CONSIDERACIONES FINALES}

El estudio ha abordado el paisaje de Muntanyes d'Ordal de manera sistémica e integrada, adoptando una visión pluriescalar ajustada a tres niveles de aproximación distintos.

En el primer nivel, el rango taxonómico I, se delimitan unidades de paisaje con gran detalle y se caracterizan según el predominio de elementos y energías; para ello se ha adaptado al lugar y características de la investigación una leyenda aplicada con éxito en otras experiencias. En el segundo nivel, el rango taxonómico II, se establecen unidades de paisaje a partir de delimitaciones de rango I; en este sentido se han generalizado las unidades de primer rango según la afinidad que mantenían con otras unidades vecinas y con el lugar donde se encontraban. En el tercer nivel, el rango taxonómico III, la delimitación de unidades se realiza recogiendo los valores empleados en los dos rangos anteriores y primando los criterios de carácter territorial; con ello se consiguen corografías que, al mismo tiempo, recogen apreciaciones de forma y contenido.

El método seguido facilita una aproximación al área de estudio en tres escalas distintas $(1: 10.000,1: 20.000$ y 1:25.000) y bajo tres enfoques de trabajo distintos, que no solo ordenan sino que también clasifican el paisaje. Además, el planteamiento utilizado propicia el 
desarrollo de ejercicios de carácter aplicado en las delimitaciones de segundo y, particularmente, primer nivel, al tiempo que favorece una primera aproximación y una buena aprehensión del lugar mediante las delimitaciones de tercer nivel.

Por último, huelga decir que la taxonomía empleada es abierta, de tal manera que permite su ampliación con otros rangos superiores, siempre en función de las dimensiones del área de estudio y en coherencia con el enfoque de trabajo que se desee adoptar.

\section{AGRADECIMIENTOS}

Durante el redactado de este artículo se ha contado con el apoyo institucional del Servei de Gestió i Evolució del Paisatge de la Universidad de Barcelona. El manuscrito original ha sido mejorado gracias a las observaciones de dos evaluadores anónimos.

\section{REFERENCIAS BIBLIOGRÁFICAS}

AROZENA, C. (1990): Los paisajes naturales de la isla de la Gomera. La Laguna. Universidad de La Laguna.

BERTRAND, G. (1968): «Paysage et géographie physique globale. Esquisse methodologique». Revue Géographique des Pyrenées et du Sud-Ouest, $\mathrm{n}^{\circ}$. 39, 249-272.

BERTRAND, G. (2000): «Le paysage et la géographie: un nouveau rendez-vous». Treballs de la Societat Catalana de Geografia, nº 50, XV, págs. 57-68.

BERTRAND, C.; BERTRAND, G. (2006): Geografia del medio ambiente. El sistema GTP: geosistema, territorio y paisaje. Granada. Universidad de Granada, 403 pp.

BOLÒS. M. (Dir.) (1992): Manual de ciencia del paisaje. Barcelona. Masson.

BOLÒS, M.; GÓMEZ ORTIZ, A. (2006): «L'Alt pirineu i Aran. Cartografia d'unitats funcionals de paisatge». IBIX, $\mathrm{n}^{\circ} 7,65-76$.

BOLÒS, M.; GÓMEZ ORTIZ, A. (2009): «La ciencia del paisaje». BUSQUETS, J.; CORTINA, A. Gestión del paisaje, Barcelona, Ariel, págs. 165-180.

BOLÒS, M.; SERRANO, D. (2008): «El mapa de paisatge, un mapa temàtic complex». Treballs de la societat catalana de Geografia, $\mathrm{n}^{\circ}$ 65, 27-37.

CHRISTIAN, C.S.; STEWART, G.A. (1968): «Methodology of integrated surveys». Aerial surveys and integrated studies. Paris. UNESCO, 233-281.

CLAVERO, P.; RASO, J. M.; MARTÍN, J. (1994): «Aproximación climatológica para un estudio de paisaje. Análisis climático de Begues» en I Coloqui Paisaje y Geosistema. Barcelona. Universidad de Barcelona.

CRUZ, L.; ESPAÑOL, I. (2009): El paisaje. De la percepción a la gestión. Madrid, LITEAM, $255 \mathrm{pp}$.

ELÍAS, L. V. (2008): «Paisaje del viñedo: patrimonio y recurso». Pasos, $\mathrm{n}^{\circ}$ 2, 137-158.

FLÓREZ-ESTRADA, I.; PÉREZ-CHACÓN, E.; ALONSO, I.; GONZÁLEZ, F.; MARTEL, F.; ROMERO, L.; SUÁREZ, M.; TORRES, C. (1994): «Aproximación metodológica a la prognosis del paisaje: la evaluación de impacto ambiental de un plan general municipal» en II Congreso de Ciencia del paisaje. Barcelona. Universidad de Barcelona, págs. 35-45. 
FOCHLER-HAUKE, G. (1953): Corología geográfica: el paisaje como objeto de la geografía regional. Tucumán. Universidad Nacional de Tucumán, 196 pp.

FROLOVA, M. (2001): «Los orígenes de la ciencia del paisaje en la geografía rusa». Scripta Nova, vol. V, no 102, 1 de diciembre de 2001. [Acceso en <http://www.ub.edu/geocrit/ sn-102.htm>]. [Última consulta: 13 de febrero de 2012].

FROLOVA, M.; MENOR, J.; CÁNCER, L. (2003): «El paisaje en las políticas públicas de Francia y España: desde la protección del monumento a la gestión del espacio». Estudios geográficos, $\mathrm{n}^{\circ}$ 64, 253, págs. 605-622.

GARCÍA ROMERO, A.; MUÑOZ JIMÉNEZ, J. (2002): El paisaje en el ámbito de la Geografía. México D.F. UNAM-Instituto de Geografía.

GÓMEZ MENDOZA, J. (2003): «Los estudios de paisaje en la Geografía española». Banco de buenas prácticas en Geografía, $\mathrm{n}^{\circ} 1,5$.

HERNÁNDEZ, L.; RUIZ, P.; NARANJO, A.; CAMINO, J.; ROMERO, L.; PÉREZ-CHACÓN; E. (1999): «Aplicaciones de las unidades de paisaje en los diagnósticos de limitaciones para acoger usos urbanos» en III Congrés de ciència del paisatge. Barcelona. Universidad de Barcelona, 91-104.

LLOP, C. (2008): «Paisatges metropolitans: policentrisme, dilatacions, multiperifèries i microperifèries», Papers, $\mathrm{n}^{\circ}$ 47, 8-13.

LLOPIS LLADÓ, N. (1947): Contribución al conocimiento de la morfoestructura de los Catalánides. Barcelona. Ariel.

LLORENTE, J. M. (1985): Los paisajes adehesados salmantinos. Salamanca. Centro de estudios salmantinos.

LÓPEZ FERNÁNDEZ, S.; LÓPEZ FERNÁNDEZ, M.L. (1985): «Geografía-Paisaje-Taxonomía». Publicaciones de Biología de la Universidad de Navarra. Serie Botánica, $\mathrm{n}^{\circ} 5$, $23-44$.

MAE (2000): Convenio Europeo del Paisaje. Madrid, Ministerio de Asuntos Exteriores. Oficina de Interpretación de Lenguas, $7 \mathrm{pp}$.

MARQUÈS, À. (1995): «La Geologia». Atles del Baix Llobregat. Barcelona. Institut Cartogràfic de Catalunya.

MARTÍN, J.; MORENO, M. C. (1996): «El Montnegre: extrem sud de la dorsal pluviomètrica meridiana de Catalunya». I Trobada d'Estudiosos del Montnegre i Corredor. Barcelona. Diputació de Barcelona.

MAS HERNÁNDEZ, R. (2000): «La urbanización de la montaña» en MARTÍNEZ DE PISÓN, E. y SANZ HERRÁINZ, C. (Ed.) Estudios sobre el paisaje. Madrid, Fundación Duques de Soria-Universidad Autónoma de Madrid, 121-140.

MATEO, J. (1984): Apuntes de geografía de los paisajes. Ciudad de la Habana. Universidad de la Habana.

MITCHELL, C. (1991): Terrain evaluation. Londres. Longman.

MUÑOZ JIMÉNEZ, J. (1981): «Paisaje-vivencia y paisaje-objeto en los planteamientos integrados de análisis geográfico» en Actas del I congreso ibérico de Geografía. Salamanca, Universidad de Salamanca, 55-66.

NOGUÉ, J.; PUIGBERT, L.; BRETCHA, G. (2009): Ordenació i gestió del paisatge a Europa. Olot, Observatori del Paisatge de Catalunya, $381 \mathrm{pp}$. 
NOGUÉ, J. (2010): «El paisaje en la ordenación del territorio. La experiencia del Observatorio del Paisaje de Cataluña», Estudios geográficos, n ${ }^{\circ}$ 269, 415-448.

PAÜL, V.; SERRANO, D. (2005). Muntanyes d'Ordal. El nom que no surt als mapes. Barcelona. Publicacions de l'Abadia de Montserrat.

PAÜL, V.; SANCHO, A.; TORT, J. (2011): «I. Marco conceptual». MOLINERO, F.; OJEDA, J.F.; TORT, J., Los paisajes agrarios de España. Madrid, Ministerio de Medio Ambiente y Medio Rural y Marino, págs. 9-38.

PÉREZ CHACÓN, E.; HERNÁNDEZ, L.; ROMERO, L.; RUIZ, P. (2005): Información, identificación, caracterización y catalogación de los paisajes de la Macaronesia. Las Palmas de Gran Canaria, Gobierno de Canarias.

PÉREZ-CHACÓN, E; SUÁREZ RODRÍGUEZ, C. (1993): «El archipiélago Chinijo». Geografía de Canarias. MORALEZ MATOS, G (dir). Las Palmas de Gran Canaria: Prensa Ibérica, págs. 516-532.

PLAZA GUTIÉRREZ, J.I. (1984): «Las unidades de paisaje del Alto Aliste», Estudios geográficos, $\mathrm{n}^{\circ} 177,455-474$.

POL, E.; CASTRECHINI, Á.; Di MASSO, A. «Paisatge i qualitat de vida» en NOGUÉ, J.; PUIGBERT, L.; BRETCHA, G. Paisatge i salut. Plecs de paisatge: Reflexions 1. Olot, Observatori del Paisatge, 36-51.

ROGER, A. (2000): Breu tractat del paisatge. Barcelona: La Campana, 215 pp.

SAZ, J. (2001): Del paisaje integrado a la cartografía de suelos. Logroño, Geoforma-Instituto de estudios turolenses.

SERRANO, D. (2006): «Canvis en els usos i les cobertes del sòl a les Muntanyes d'Ordal, Barcelona (1717-2000)» en Paisatge, territori $i$ societat a les terres de parla catalana. Actes del V Congrés de la CCEPC. Valls, Cossetània Edicions, 55-66.

SERRANO, D.; PIQUER, M. (2006): «Les Muntanyes d'Ordal i els moviments socials en defensa dels seus valors paisatgístics» en $4^{e s}$ Jornades d'estudi del patrimoni del Baix Llobregat. Barcelona, Consell comarcal del Baix Llobregat, 103-112.

SERRANO, D.; BENNASSAR, N. (2009): «La diversidad de planteamientos en los estudios de paisaje. Reflexiones en torno a una cuestión candente». Uned. Espacio, Tiempo y Forma. Serie VI. Nueva época, 2, págs. 21-27.

SOLÉ, Ll. (Dir.) (1975): «Hoja 420, Hospitalet de Llobregat». Mapa geológico de España 1: 50 000. Madrid. Servicio de Publicaciones del Ministerio de Industria.

TARROJA, À. (2006): «Transformaciones territoriales y valoración social del paisaje» en MATA, R.; TARROJA, À. (Coord.) El paisaje y la gestión del territorio. Barcelona. Diputació de Barcelona, 41-50.

ZOIDO, F. (1998): Geografía y ordenación del territorio. Íber, 16, 19-31. 